\title{
Development of the Breastfeeding Support Scale to measure breastfeeding support from lay and professional persons, and its predictive validity in Japan
}

\author{
Keiko Nanishi ${ }^{\text {Corresp., } 1}$, Joseph Green ${ }^{1}$, Hiroko Hongo ${ }^{2}$ \\ 1 Office of International Academic Affairs, Graduate School of Medicine, The University of Tokyo, Tokyo, Japan \\ 2 Department of Community and Global Health, Graduate School of Medicine, The University of Tokyo, Tokyo, Japan \\ Corresponding Author: Keiko Nanishi \\ Email address: keiko50@m.u-tokyo.ac.jp
}

Background. International and national organizations recommend exclusive breastfeeding for the first six months of life, but many women stop earlier. Lay and professional persons can support mothers' efforts to overcome breastfeeding difficulties. Considering breastfeeding support to comprise emotional support, practical help, and information offered to women who desire to breastfeed (by professionals, family members, and others), we developed and tested a scale to measure it in Japan. Methods. A total of 31 items were generated by literature review and from the authors' clinical experiences. Those items were tested with 243 mothers who visited public health centers in Tokyo for their infant's health check-up 3 months after birth. Breastfeeding support and infant feeding status were then assessed 5 months after birth. All the data were collected by using self-administered questionnaires. Results. On the basis of the results of factor analysis, the number of items was reduced to 11 . There were three factors: support from breastfeeding peers and from people in specifically named healthcare professions, practical help, and support from people the mother can rely on to help meet emotional needs and address breastfeeding concerns. Internal-consistency reliability (alpha) of scores on the 11-item scale was 0.83 when measured 3 months postpartum and 0.85 when measured 5 months postpartum. Higher scores on the 11-item scale 3 months postpartum were associated with more breastfeeding exclusivity both at that time (Kruskal-Wallis test, chi-squared $=14.871, \mathrm{df}=3, \mathrm{n}=211, \mathrm{p}=0.002$, eta-squared $=$ 0.071 ) and also 5 months postpartum (Kruskal-Wallis test, chi-squared $=8.556, \mathrm{df}=3, \mathrm{n}=$ $159, p=0.036$, eta-squared $=0.054)$. Further, the area under the Receiver Operating Characteristic curve was $0.73(95 \% \mathrm{Cl} 0.57$ to 0.88$)$, which indicates that scores on the 11 item scale 3 months postpartum may be useful to predict which mothers will be less exclusive in breastfeeding 5 months postpartum. In conclusion, scores on this 11-item scale were reasonably reliable and valid for measuring breastfeeding support provided by 
lay and professional persons to mothers in Japan. Further research is required to evaluate this scale's applicability in other settings. 


\section{Development of the Breastfeeding Support Scale to}

\section{2 measure breastfeeding support from lay and professional}

\section{3 persons, and its predictive validity in Japan}

4

5 Keiko Nanishi ${ }^{1}$, Joseph Green ${ }^{1}$, Hiroko Hongo ${ }^{2}$

6

$7{ }^{1}$ Office of International Academic Affairs, Graduate School of Medicine, the University of

8 Tokyo, Bunkyo-ku, Tokyo, Japan

$9{ }^{2}$ Department of Community and Global Health, Graduate School of Medicine, the University of

12 Corresponding Author:

13

Tokyo, Bunkyo-ku, Tokyo, Japan

Keiko Nanishi ${ }^{1}$

7-3-1 Hongo, Bunkyo-ku, Tokyo, 1130033, Japan

Email address: keiko50@m.u-tokyo.ac.jp

\section{Abstract}

Background. International and national organizations recommend exclusive breastfeeding for the first six months of life, but many women stop earlier. Lay and professional persons can support mothers' efforts to overcome breastfeeding difficulties. Considering breastfeeding support to comprise emotional support, practical help, and information offered to women who desire to breastfeed (by professionals, family members, and others), we developed and tested a scale to measure it in Japan. Methods. A total of 31 items were generated by literature review and from the authors' clinical experiences. Those items were tested with 243 mothers who visited public health centers in Tokyo for their infant's health check-up 3 months after birth. Breastfeeding support and infant feeding status were then assessed 5 months after birth. All the data were collected by using self-administered questionnaires. 
29 Results. On the basis of the results of factor analysis, the number of items was reduced to 11. There were three factors: support from breastfeeding peers and from people in specifically named healthcare professions, practical help, and support from people the mother can rely on to help meet emotional needs and address breastfeeding concerns. Internal-consistency reliability (alpha) of scores on the 11-item scale was 0.83 when measured 3 months postpartum and 0.85 when measured 5 months postpartum. Higher scores on the 11-item scale 3 months postpartum were associated with more breastfeeding exclusivity both at that time (Kruskal-Wallis test, chi-squared $=14.871, \mathrm{df}$ $=3, n=211, p=0.002$, eta-squared $=0.071$ ) and also 5 months postpartum (KruskalWallis test, chi-squared $=8.556, \mathrm{df}=3, \mathrm{n}=159, \mathrm{p}=0.036$, eta-squared $=0.054$ ). Further, the area under the Receiver Operating Characteristic curve was 0.73 (95\% Cl 0.57 to 0.88 ), which indicates that scores on the 11-item scale 3 months postpartum may be useful to predict which mothers will be less exclusive in breastfeeding 5 months postpartum. In conclusion, scores on this 11-item scale were reasonably reliable and valid for measuring breastfeeding support provided by lay and professional persons to mothers in Japan. Further research is required to evaluate this scale's applicability in other settings.

\section{Introduction}

International and national organizations recommend exclusive breastfeeding for the first six months of life (World Health Organization 2003). Nonetheless, many mothers who intend to breastfeed for six months or longer in fact stop earlier (UNICEF 2019). Early cessation can have various causes. Among them are perceived insufficiency of breast milk (Balogun et al. 2015; Dennis 2002), difficulty integrating breastfeeding with work outside the home and with other aspects of life (Balogun et al. 2015; Sayres \& Visentin 2018), and social circumstances that are not conducive to breastfeeding (Brown 2017; Robinson et al. 2019). In 2019, only $42 \%$ of infants under 6 months were exclusively breastfed globally (UNICEF 2019).

Lay persons and medical professionals can help mothers overcome those challenges (Hannula et al. 2008; McFadden et al. 2017). In Brazil, regular home visits by trained community health workers increased the rate of exclusive breastfeeding 4 
60 months postpartum (Leite et al. 2005) and 6 months postpartum (Coutinho et al. 2005).

61 A study in Canada showed that telephone-based support from trained peers was

62 effective in maintaining breastfeeding to 3 months postpartum and in improving

63 satisfaction with the infant-feeding experience (Dennis et al. 2002). An intervention

64 study in a hospital serving a large population of low-income Latinas found that support

65 from trained peers decreased the rate of early cessation of breastfeeding within 3

66 months postpartum. A recent systematic review concluded that providing women with

67 additional organized support helps them breastfeed their babies longer (McFadden et

68 al. 2017). Also, studies in Sweden and elsewhere showed that women often value

69 emotional support for breastfeeding and practical help for child care from a partner, family members, or others they rely on (Brown et al. 2011; Cato et al. 2020; Juengst et al. 2019; Schmied et al. 2011). Therefore, the availability of support is a key to the continuation of breastfeeding, and tools for measuring it can be useful in identifying needs and in evaluating the effectiveness of interventions.

Several scales for measuring breastfeeding support are available. The Hughes Breastfeeding Support Scale (HBSS) was developed more than 35 years ago in the United States (Hughes 1984). However, since then it has not been widely used and there are very few results of validation testing. In 1992 Matich and Sims described a scale for measuring breastfeeding support during pregnancy and 3-to-4 weeks postpartum (Matich \& Sims 1992) in the United States, although its applicability up to 6 months postpartum remained unclear. Scales have been developed more recently for measuring breastfeeding support among adolescents (Grassley et al. 2013), and working mothers (Bai et al. 2008; Greene \& Olson 2008) in the United States, and for mothers in Uganda (Boateng et al. 2018).

The support needed to continue breastfeeding may differ according to social context (McFadden et al. 2017). We considered that the existing scales may not be appropriate for measuring breastfeeding support among the majority of mothers in Japan. In Japan, only $0.9 \%$ of newborns are born to adolescent mothers (Ministry of Health, Labour and Welfare. 2019a), and the majority of women who have a baby below 6 months of age are not in the workforce ( $54 \%$ had already resigned from their job and 
91 according to a recent national survey) (Ministry of Health, Labour and Welfare. 2019b).

92 While a majority of women stay at home to take care of her newborns, only $2 \%$ of

93 fathers working in a permanent position take child-care leave (Ministry of Health, Labour

94 and Welfare. 2019a; Ministry of Health, Labour and Welfare. 2019b), which suggests

95 that there is a need to assess breastfeeding support in the context of imbalanced

96 childcare commitment between the parents. More than $93 \%$ of pregnant women in

97 Japan intend to breastfeed and a vast majority initiate breastfeeding, but only $55 \%$ were

98 found to be predominantly breastfeeding three months postpartum (Equal Employment,

99 Children and Families Bureau, Ministry of Health, Labour and Welfare. 2016.). That gap

100 between original intention and later practice might be due to a lack of support (Inoue et

101 al. 2012; Sriraman \& Kellams 2016). Appropriate infant feeding support early in the

102 postpartum period is recognized as important by Unicef and the $\mathrm{WHO}$, and compliance

103 with recommendations can be evaluated (Unicef \& World Health Organization 2018).

104 However, support to continue breastfeeding, including support from healthcare

105 professionals and from others, has not been quantified in a way that is relevant to

106 Japan. Consequently, in Japan the needs for support among lactating mothers and the

107 effectiveness of breastfeeding support remained unclear. Therefore, we developed a

108 scale to measure breastfeeding support 3 and 5 months postpartum among mothers

109 living in Japan and tested its reliability and predictive validity. In this study, we

110 considered breastfeeding support as comprising emotional support, practical help, and

111 information offered to women who desire to breastfeed by professionals, family

112 members, and others.

114 Materials \& Methods

115 Item development

Based on the literature on social support and breastfeeding support, the authors conceptualized a framework for the scale. That framework consists of support sources and support type (Table S1). Previous studies in Japan suggested that socioenvironmental factors influence breastfeeding. Those factors include appropriate professional support, support from the husband, and the option for mothers to take paid maternity leave for more than six months (Inoue et al. 2012; Kaneko et al. 2006). To 
122 reflect the fact that breastfeeding is often influenced by socio-environmental factors, we 123 adopted the ecological model (Institute of Medicine. 2000) when considering the source 124 of breastfeeding support. Specifically, we considered that breastfeeding support is

125

126

127

128

129

130

131

132

133

134

135

136

137

138

139

140

141

142

143

144

145

146

147

148

149

150

151

152 provided by social networks that include family, close friends, peers, health professionals, as well as by mass media and others. In Japan, the marketing of formula milk for babies is not regulated by law, and companies "support" breastfeeding through websites, social networking services, childcare magazines, and face-to-face counseling. Considering the possibility that mothers recognize them as a source of information to support their breastfeeding, we included companies that produce and sell formula and related goods as a possible source of support. Regarding the types of support, the theoretical concept of social support described by House was also considered (House 1981). Social support is defined as the help provided through social relationships and interactions. House distinguished among four main types of social support: emotional (expressions of empathy, love, trust, and caring), instrumental (tangible aid and services), informational (advice, suggestions, and information), and appraisal (information that is useful for self-evaluation) (House 1981).

Candidate question-items were developed with reference to the literature on social support, breastfeeding support, and factors associated with breastfeeding, and also on the basis of two of the authors' $(\mathrm{KN}$ and $\mathrm{HH})$ clinical experience in supporting lactating women. To develop items that reflect support from each support source and type, the first author purposively referred to the literature on factors associated with breastfeeding among women who are healthy, live in high-income countries, and have a single healthy full-term baby (Dennis 2002; Kaneko et al. 2006; Labbok \& Taylor 2008), and also reviewed other literature on breastfeeding support (Brown et al. 2011; Burns et al. 2010; Hannula et al. 2008; Hughes 1984; Ito et al. 2013; Matich \& Sims 1992; Schmied et al. 2011). Table S2 summarizes the findings of each study reviewed and the items created based on those findings. Reports by Japan's government on the feeding of infants and young children were also reviewed (Equal Employment Children and Families Bureau, Ministry of Health, Labour and Welfare 2006; Ministry of Health, Labour and Welfare 2011). Those reports mentioned that three-to-five months postpartum was a common time for mothers to be concerned about infant feeding, but 
153 they had no specific information regarding needs for breastfeeding support. Studies on 154 breastfeeding support for working mothers were not included in the literature review 155 because we studied new mothers in the general population, most of whom either were 156 not employed or were on maternity leave.

In addition to the question-items derived from the literature review, the first and

158

159

160

161

162

163

164

165

166

167

168

169

170

171

172

173

174

175

176

177

178

179

180

181

182

183

the third authors added candidate items on the basis of their experience in clinical pediatrics $(\mathrm{KN})$ and as International Board-Certified Lactation Consultants ( $\mathrm{KN}$ and $\mathrm{HH}$ ). Item 6 "I have received free samples or discount coupons for formula milk" and item 20 "In medical facilities I see posters or logos about formula milk" were developed from the idea that free samples and logos at health facilities and elsewhere might make mothers feel that formula is a normative standard supported by health professionals and others while exclusive breastfeeding is considered an extreme choice. Item 18 "I have heard that I must not take any medicine while breastfeeding" and item 22 "I have heard that there are certain things I should not eat while breastfeeding" were created because the authors notice that lactating mothers are often advised to avoid all medications and to avoid specific foods, and that this misinformation is provided both by health professionals and by others. Item 28 "When I leave my baby with other people, I think it will be problematic for them if my baby does not accept a bottle of formula milk" was developed because the authors noticed that mothers often use bottles in the belief that it reduces the burden on other caregivers, a belief that might reflect inappropriate or insufficient breastfeeding support.

The items were developed in Japanese. A total of 31 items were generated to provide adequate redundancy within each of the four types of support listed above. Some items were positively worded and others were negatively worded. Response choices used a 5-point Likert-type scale from 1 (not agree) through 5 (agree). Those 31 items can be found in Table S3, with English translations.

\section{Content validation testing}

As recommended by Fitzner to improve item validity, the items were reviewed by a panel of experts to assess whether they adequately covered each of the concepts to be measured (Fitzner 2007). The panel comprised five specialists, all of whom were 
184 university professors in nursing or midwifery who had clinical experience supporting 185 breastfeeding mothers. Content validity was tested quantitatively by using the Content 186 Validity Index (CVI). CVIs can be computed for each item in a scale (item-level CVI) as 187 well as for the scale as a whole (scale CVI) (Polit et al. 2007). To calculate item-level 188 CVIs, each member of the panel of experts rated each item independently on a 4-point Likert-type scale, with higher ratings indicating greater relevance. For each item, the item-level CVI was computed as the number of experts who gave a rating of either 3 or 4 , divided by 5 (the total number of experts). The scale-level CVI was assessed by two 192 methods: the proportion of items that was rated either 3 or 4 by all five experts 193 (universal agreement method), and the average of all item-level CVIs (averaging 194 method).

Item-level CVIs for each item are shown in Table S4. The scale-level CVI for the 196 31 items was 0.94 by the universal agreement method, and 0.99 by the averaging 197 method, both of which are above the recommended minimum of 0.90 (Polit et al. 2007). Two items for which the CVI was 0.80 were modified after discussion with the expert 199 panel, and were kept for further analysis.

In addition to being asked to rate the items for the CVIs, the experts were also

201

202 203

204

205 206 207 208 209

210

211

212 213 asked to give comments and suggestions regarding clarity and readability of each item. Those comments and suggestions led to minor editorial revisions.

\section{Pilot testing}

The items were then pilot-tested about a month prior to the main survey with a convenient sample of 27 healthy mothers who visited a public health center in Tokyo's Adachi Ward for their infant's 3-month health check-up. After the participants completed the instrument, which took each mother about 5 minutes, the first author interviewed them individually to evaluate understandability, face validity, and the instrument's format. Based on feedback from the first 14 mothers, the wordings of eight items were slightly modified. Then 13 other mothers completed the revised scale, and they found all the items to be clear. None of the mothers noted any problem with the format. 
214 Design and Participants

215 This was a longitudinal study with a survey three months after birth and a follow216 up survey two months later. After the pilot study, we recruited participants for the main 217 study. Mothers who visited any one of four health centers in Adachi Ward from October 218 to December, 2014 for their infant's 3-month health check-up were invited to participate 219 in the study, if they were at least 18 years old, had a singleton infant, and were fluent in 220 Japanese. Adachi Ward is one of the 23 wards of central Tokyo, and is primarily a 221 residential area. The healthy life expectancy of women in Adachi Ward was the shortest 222 among the 23 wards in Tokyo in 2016 (Toukyouto hukushi hoken kyoku. 2019) and it 223 has no Baby-Friendly certified hospital. Adachi Ward had five health centers but one 224 was not included in this study because it did not have enough space for conducting the 225 survey. Among 414 mothers who were approached, 376 (91\%) consented to participate 226 in the study. Mothers were excluded if they or their infants had a medical condition that 227 could significantly interfere with breastfeeding. Those conditions included preterm birth 228 ( $n=18)$, low birth weight $(n=22)$, macrosomia $(n=3)$, congenital abnormality of the 229 infant $(\mathrm{n}=9)$, and a history of admission to an NICU $(\mathrm{n}=3)$. In addition, 20 mothers 230 were excluded because they reported that during pregnancy they had intended formula 231 feeding, and 7 mothers were excluded because they visited the health center earlier or later than expected (their infants were younger than 3 months or older than 5 months). Some mothers met more than one exclusion criterion. After the exclusion criteria described above were applied, 243 mothers participated to the study.

All the data were collected by using self-administered questionnaires. The first survey was conducted when the participants were waiting for their appointment at a health center for their infants' 3-month health checkup. The follow-up survey was conducted by postal mail. Among the 243 mothers who completed the first survey, 177 $(73 \%)$ returned the follow-up survey.

240

\section{Psychometric testing}

Psychometric testing included factor analysis (described in more detail below) and computation of internal-consistency reliability (coefficient alpha). For validation tests, we hypothesized that higher scores on the breastfeeding social support scale, 
245 indicating more support, would be associated with better family functioning and with 246 better infant-feeding status at 3 and 5 months. Family functioning and infant-feeding 247 status were measured as described below.

248

249 Family Apgar

250

251

As a construct-validation test, we measured family functioning and computed its correlation with scores on the new breastfeeding social support scale. The Japanese

252 version of the Family Apgar scale was used to measure family functioning. It comprises five question-items regarding family adaptation, partnership, growth, affection, and resolve. Responses were on a 3-point (0,1, and 2) Likert-type scale, yielding minimum and maximum total scores of 0 and 10 . Higher total scores indicate better family 256 functioning. Internal-consistency reliability (coefficient alpha) for the Family Apgar scale was 0.77 in this study.

258

259

\section{Infant-feeding status}

260

Information on infant-feeding status 3 months and 5 months after birth came from 261 the mothers' reports. Mothers were asked which of the following six options best 262 described their infant-feeding method over the previous 24 hours: (1) full breastfeeding (exclusive and almost exclusive breastfeeding), (2) high partial breastfeeding

264 (breastfeeding for more than $80 \%$ of all feedings), (3) medium partial breastfeeding 265 (breastfeeding for $20 \%-80 \%$ of all feedings), (4) low partial breastfeeding 266 (breastfeeding for less than $20 \%$ of all feedings), (5) token breastfeeding (occasional 267 breastfeeding, not for nutritive purposes), and (6) formula feeding (formula feeding only) 268 (Labbok \& Krasovec 1990; Labbok \& Coffin 1997).

\section{Analysis}

Factor analysis was done to determine the factor structure and to identify items 272 that contribute to the factors. After the structure and the items to be included in the 273 scale were identified, the reliability and the validity of the scale were tested. To assess 274 reliability, coefficient alpha was computed for the scores on the scale as a whole and for 275 the scores on each subscale. Regarding validity, three hypotheses were tested. First, 
276 the total score on the scale was hypothesized to correlate (Pearson's correlation 277 coefficient) with the score on the Family Apgar scale. Second, the total score on the 278 scale 3 months postpartum was hypothesized to be associated with the infant feeding 279 status at that time, and also with the infant feeding status 5 months postpartum. The 280 Kruskal-Wallis test was used to test that hypothesis. That test was used because it is a 281 non-parametric one-way analysis of variance (ANOVA). It uses the ranks of the data 282 rather than their absolute values. This has the potential advantage of not assuming that 283 residuals are normally distributed, so it may be applicable even when the data do not 284 meet that condition. Because it tests for equal medians among all groups, the results of 285 the Kruskal-Wallis test are interpreted in a way that is analogous to the way in which the 286 results of the more commonly used parametric ANOVA are interpreted. The difference is that with the Kruskal-Wallis test the interpretation refers to medians whereas with parametric ANOVA the interpretation refers to means. For example, a p value less than 0.05 would indicate that the median of the population of one or more of the groups is not the same as the median of the population of one or more of the other groups. The effect size (etasquared) was computed as chi-squared/(n-1). Finally, the area under the Receiver Operating Characteristic curve was calculated to assess the degree to which the total score and each subscale score 3 months postpartum could be used to predict which mothers would be in a low category of infant-feeding status 5 months postpartum.

Ethical Considerations

Ethical approval was obtained from the Research Ethics Committee of the Graduate School of Medicine at the University of Tokyo (Ethical Application Ref:10620), and written informed consent was received from all participants.

\section{Results}

\section{Characteristics of participants and infant-feeding status}

Characteristics of participants are shown in Table 1. Their mean age was 31.7 306 (SD 5.0) years. Among the 243 participants, 197 (81.1\%) had a vaginal delivery, 144 $(59.3 \%)$ were primiparas, $157(65.6 \%)$ indicated that during pregnancy they had 
307 intended to breastfeed exclusively, and 84 (34.6\%) had previous experience of any 308 breastfeeding for more than five months. Fourteen mothers (5.9\%) were working at 3 309 months postpartum and an additional $12(4.9 \%)$ had a plan to return to work outside the 310 home before 6 months postpartum. Compared with those who returned the follow-up 311 survey, those who did not return it were younger, less educated, and more likely to be 312 single mothers. However, there was no significant difference between the two groups in 313 mode of delivery, intention to breastfeed, previous experience breastfeeding, parity, country in which the participant was raised, working status, or financial status.

Table 2 shows infant feeding status at the time of the survey. Three months 316 postpartum, 137 (56.4\%) reported exclusive breastfeeding within the 24 hours before the survey. Five months postpartum, that number was 109 (61.6\% of those who responded). Not many were token feeding $(4(1.7 \%)$ at 3 months postpartum and 2 $(1.1 \%)$ at 5 months postpartum) or completely formula feeding (22 (9.1\%) at 3 months postpartum and $14(7.9 \%)$ at 5 months postpartum). Among the 159 women who

321

322 323 324 325 326 327 reported their feeding method both 3 months and 5 months postpartum, during the interval between those two reports 7 women increased the exclusivity of breastfeeding, while 22 either reduced the exclusivity of breastfeeding $(n=18)$ or stopped breastfeeding $(n=4)$.

\section{Initial psychometric testing, and modifications based on those results}

The mean and SD of each of the 31 items' scores is shown in Table 3. The scores on items 16 and 27 had particularly low SDs.

The scree plot resulting from factor analysis of the 31 items (Figure 1) clearly had two sections, which were separated by an "elbow" at factor number 4. Looking at the curve in Figure 1 from left to right, the eigenvalues decrease very "steeply" between factor number 1 and factor number 3 , but much more gradually starting at factor number 4. This indicated that the number of factors to be retained was three (Figure 1). That is, much of the variability in the responses to the 31 questions could be explained by variability in only three underlying factors. This was not unexpected, given that the 31 questions were intended to ask about a smaller number of separate sources and types of breastfeeding support. Figure 1 was interpreted as meaning that the 31 questions 
338

339

340

341

342

343

344

345

346

347

348

349

350

351

352

353

354

355

356

357

358

359

360

361

362

363

364

365

366

367

were measuring three underlying variables. Next, with the number of factors restricted

to three, after varimax rotation the items with factor loadings less than 0.4 were deleted:

Those were items $6,10,11,12,13,14,15,16,18,19,20,22,23,24,25,27,28$, and

30. With the remaining 13 items, the same factor analysis procedure was done again and items 21 and 29 were omitted. By that process, the only items retained were those that were best for measuring the three underlying factors.

The resulting scale had 11 items, and factor analysis with those 11 items confirmed that each of them had a loading greater than 0.4 on one, and only one, of the three factors (Table 4). Items 7, 8, 9, and 31 loaded strongly on the first factor. Because of the content that those four items had in common, they were considered to comprise a subscale measuring support from breastfeeding peers and from people in specifically named healthcare professions. Items 2, 5, and 26 loaded strongly on the second factor. Because of the content that those three items had in common, they were considered to comprise a subscale measuring practical help. Similarly, items 1, 3, 4, and 17 loaded strongly on the third factor, and they were considered to comprise a subscale measuring support from people the mother can rely on to help meet emotional needs and address breastfeeding concerns.

\section{Reliability testing}

Three months postpartum, coefficient alpha of the scores on the 11-item scale was 0.83 , and 5 months postpartum it was 0.85 . Three months postpartum, the alphas for the scores on the subscales were 0.78 (breastfeeding peers and named professions), 0.80 (practical help), and 0.81 (support to meet emotional needs). Five months postpartum, the alphas for the scores on the subscales were 0.79 (breastfeeding peers and named professions), 0.86 (practical help), and 0.81 (support to meet emotional needs).

\section{Validation testing}

We hypothesized that mothers in well-functioning families would have higher scores on the 11-item breastfeeding support scale. That hypothesis was supported by 
368 the positive correlation between the 11-item scale score and the Family Apgar score 3 369 months postpartum $(r=.47, p<0.001)$.

370

371

372

373

374

375

376

377

378

379

380

381

382

383

384

385

386

387

388

389

390

391

\section{2}

393

394

395

396

397

398

Table 5 shows the mean scale scores ( 11 items) of women in each category of infant-feeding status 3 and 5 months postpartum. Among the mothers who completed the scale 3 months postpartum, very few were token feeding $(n=2)$ or completely formula feeding $(n=3) 5$ months postpartum, so those two categories were combined with the low-partial breastfeeding category $(n=6)$ to make a group of 11 mothers. Higher scores on the 11-item scale 3 months postpartum were associated with more breastfeeding exclusivity both at that time and also 2 months later (i.e. both 3 months and also 5 months postpartum). Specifically, the results of the Kruskal-Wallis test 3 months postpartum were chi-squared $=14.871(\mathrm{df}=3, \mathrm{n}=211), \mathrm{p}=0.002$, eta-squared $=0.071$, and the results of the same test 5 months postpartum were chi-squared $=$ $8.556(\mathrm{df}=3, \mathrm{n}=159), \mathrm{p}=0.036$, eta-squared $=0.054$.

The area under the Receiver Operating Characteristic curve (AUC) was 0.73 (95\% Cl 0.57 to 0.88$)$, which indicates that scores on the 11 -item scale 3 months postpartum may be useful to predict which mothers will be in a low category of infantfeeding status (i.e., low-partial breastfeeding, token breastfeeding, or formula feeding) 5 months postpartum. Regarding the subscales, the AUC was 0.78 ( $95 \% \mathrm{Cl} 0.63$ to 0.94 ) for the subscale measuring support from breastfeeding peers and from people in specifically named healthcare professions, $0.44(95 \% \mathrm{Cl} 0.27$ to 0.94$)$ for the subscale measuring practical help, and $0.74(95 \% \mathrm{Cl} 0.60$ to 0.88$)$ for the subscale measuring support from people the mother can rely on to help meet emotional needs and address breastfeeding concerns.

\section{Discussion}

The purpose of the study was to develop an instrument for measuring support that might help mothers continue breastfeeding. After the initial psychometric testing and modifications based on the results of those tests, the final version of the Breastfeeding Support Scale had 11 items with a three-factor structure: support from breastfeeding peers and from people in specifically named healthcare professions, practical help, and support from people the mother can rely on to help meet emotional needs and address 
399

400

401

402

403

404

405

406

407

408

409

410

411

412

413

414

415

416

417

418

419

420

421

422

423

424

425

426

427

428

breastfeeding concerns. The scores were reasonably reliable and valid for measuring breastfeeding support.

The structure of the scale is consistent with previous studies about breastfeeding support in developed countries (Emmott \& Mace 2015; Emmott et al. 2020; Fox et al. 2015; Negron et al. 2013; Schmied et al. 2011). Those studies indicated that the effectiveness of breastfeeding support is a complex function of the provider of support and the type of support. Emmott et al., found that mothers who received support from a wide network of people including family, friends, health professionals, and trained peer supporters breastfed longer than those who did not receive much support or who received only family-based support (Emmott et al. 2020). Also, previous studies suggested that breastfeeding support includes informational support (Emmott \& Mace 2015), emotional support (Fox et al. 2015; Negron et al. 2013; Schmied et al. 2011), and practical support (Emmott \& Mace 2015; Negron et al. 2013). The Breastfeeding Support Scale has three factors, with each factor reflecting both a source and a type of support. The first factor covers informational support and appraisal from breastfeeding peers and from people in specifically named healthcare professions. The second factor covers practical support that gives mothers enough time for breastfeeding, childcare, and rest. The third factor reflects having somebody who responds to mothers' emotional needs to continue breastfeeding.

When we developed the candidate items for the scale, we tried to cover a wide range of potential sources of support: media, infant formula companies, and the socialcultural environment. Some of those candidate items mentioned informational support from media (i.e., "Information from books, magazines, and the Internet is useful for breastfeeding."), from infant formula companies (i.e., "I see formula milk with product information saying that breastmilk and artificial milk do not differ much in their health benefits for babies.", which is reverse scored), and from a breastfeeding-friendly environment (i.e., "I can breastfeed comfortably when I'm out and about."). None of the candidate items that asked about support from media, infant formula companies, and the social-cultural environment remained after the factor analysis. This indicates that, among these mothers, positive and negative influences from media, infant formula 
429

430

431

432

433

434

435

436

437

438

439

440

441

442

443

444

445

446

447

448

449

450

451

452

453

454

455

456

457

458

459

companies, and the social-cultural environment are not strongly associated with support from family, friends, health professionals, and trained peer supporters.

Psychometric testing of the Breastfeeding Support Scale among mothers in Japan indicated that it had reasonable reliability and validity to measure breastfeeding support both 3 and 5 months postpartum. At both times, the values of alpha for the overall scale and for each of the three subscales were all substantially higher than 0.7 , which is often used as a minimum for group-level comparisons. The results of all three validation tests were as hypothesized. First, the total score on the Breastfeeding Support Scale was correlated with the score on the Family Apgar scale, which measured family functioning. Second, the total score on the Breastfeeding Support Scale was associated with infant feeding status 3 months and 5 months postpartum. Finally, the area under the Receiver Operating Characteristic curve indicated that the total score of the Breastfeeding Support Scale could be used to predict which mothers would be in a low category of infant-feeding status 5 months postpartum.

Consistent with previous studies (Emmott et al. 2020), the results of the present study suggest that different types of support from different sources might have different effects on breastfeeding. The AUCs of each subscale suggested that peer and professional support, and having somebody who responded to emotional needs, are the keys to higher breastfeeding exclusivity. In contrast, practical help, including having someone who helps with housework and childrearing, did not clearly predict breastfeeding 2 months later. That might suggest such practical help does not necessarily increase breastfeeding exclusivity as previously indicated in studies in Japan (Ito et al. 2013) and the UK (Emmott \& Mace 2015). A possible explanation might be fathers' insufficient knowledge and skills regarding breastfeeding support. Another reason might be the significant gender gap in Japan in unpaid housework. When fathers become more involved in housework and childrearing, practical help, which is usually offered by a partner, may impact breastfeeding outcomes. However, the wide range of the confidence interval of the AUC for the practical help subscale suggests that more information may be required before that finding can be interpreted clearly.

There are several limitations to this study. The study was conducted in four public health centers in Tokyo Japan, so generalizations to populations in other areas 
460

461

462

463

464

465

466

467

468

469

470

471

472

473

474

475

476

477

478

479

480

481

482

483

484

485

486

487

488

489

490

should proceed only with caution. Mothers younger than 18 years old were not included and the majority of the participants were on paid leave or were not working outside their home, so further testing may be needed before the scale is used with adolescents or with working mothers. In addition, after the data were collected Japan's Ministry of Health, Labor and Welfare released a revised version of its guidelines for health professionals on the feeding of infants and young children (Jyunyuu rinyuu no shien gaido kaitei ni kannsuru kennkyuukai. 2019). In that revised version, the term "breastfeeding promotion" was omitted and the 54-page document has only two sentences regarding the benefits of breastfeeding. Those guidelines might discourage professional breastfeeding support in Japan. Further testing may be necessary to understand how the present scale performs after that policy change. The literature review to develop the items was also done more than six years ago, however, according to our knowledge there has been no literature published in Japan that would suggest a need to revise the scale. Finally, as all the data were collected by self-report, there might be social desirability bias, such as breastfeeding reported as more exclusive or support from family rated better. The English translation of the scale provided here is to be used for informational purposes only, so further psychometric testing is required to assess reliability and validity outside Japan.

\section{Conclusions}

Initial evidence favors the use of the Breastfeeding Support Scale among mothers in Japan to measure breastfeeding support provided by persons a wide range of people including peers, family, and professionals. Further research is required to evaluate the scale's applicability in other settings.

\section{Acknowledgements}

The authors are grateful to the staff members of the Adachi public health center for their help in conducting the study. We also thank the following researchers for their critical review of the contents of the scale: Dr. Shigemi Iriyama, Dr. Junko Miyazawa, Dr.

Masako Matsunaga, Dr. Megumi Haruna, and Dr. Noriko Toyama. 
491

\section{References}

493

494

495

496

497

498

499

500

501

502

503

504

505

506

507

508

509

510

511

512

513

514

515

516

517

518

519

520

521

522

523

524

525

Bai Y, Peng CY, and Fly AD. 2008. Validation of a short questionnaire to assess mothers' perception of workplace breastfeeding support. J Am Diet Assoc 108:1221-1225. 10.1016/j.jada.2008.04.018

Balogun OO, Dagvadorj A, Anigo KM, Ota E, and Sasaki S. 2015. Factors influencing breastfeeding exclusivity during the first 6 months of life in developing countries: a quantitative and qualitative systematic review. Matern Child Nutr 11:433-451. $10.1111 / \mathrm{mcn} .12180$

Boateng GO, Martin SL, Collins SM, Natamba BK, and Young SL. 2018. Measuring exclusive breastfeeding social support: Scale development and validation in Uganda. Matern Child Nutr 14:e12579. 10.1111/mcn.12579

Brown A. 2017. Breastfeeding as a public health responsibility: a review of the evidence. $J$ Hum Nutr Diet 30:759-770. 10.1111/jhn.12496

Brown A, Raynor P, and Lee M. 2011. Young mothers who choose to breast feed: the importance of being part of a supportive breast-feeding community. Midwifery 27:53-59. 10.1016/j.midw.2009.09.004

Burns E, Schmied V, Sheehan A, and Fenwick J. 2010. A meta-ethnographic synthesis of women's experience of breastfeeding. Matern Child Nutr 6:201-219. 10.1111/j.17408709.2009.00209.x

Cato K, Sylvén SM, Henriksson HW, and Rubertsson C. 2020. Breastfeeding as a balancing act - pregnant Swedish women's voices on breastfeeding. Int Breastfeed J 15:16. 10.1186/s13006-020-00257-0

Coutinho SB, de Lira PI, de Carvalho Lima M, and Ashworth A. 2005. Comparison of the effect of two systems for the promotion of exclusive breastfeeding. Lancet 366:1094-1100. 10.1016/S0140-6736(05)67421-1

Dennis CL. 2002. Breastfeeding initiation and duration: a 1990-2000 literature review. J Obstet Gynecol Neonatal Nurs 31:12-32.

Dennis CL, Hodnett E, Gallop R, and Chalmers B. 2002. The effect of peer support on breastfeeding duration among primiparous women: a randomized controlled trial. CMAJ 166:21-28.

Emmott EH, and Mace R. 2015. Practical Support from Fathers and Grandmothers Is Associated with Lower Levels of Breastfeeding in the UK Millennium Cohort Study. PLoS One 10:e0133547. 10.1371/journal.pone.0133547 
526 Emmott EH, Page AE, and Myers S. 2020. Typologies of postnatal support and breastfeeding at

527

528

529

530

531

532

533

534

535

536

537

538

539

540

541

542

543

544

545

546

547

548

549

550

551

552

553

554

555

556

557

558

559

two months in the UK. Soc Sci Med 246:112791. 10.1016/j.socscimed.2020.112791

Equal Employment Children and Families Bureau, Ministry of Health, Labour and Welfare. 2006. Reports on infant and young child feeding 2005. Tokyo,Japan: Ministry of Health, Labour and Welfare.[In Japanese]

Equal Employment, Children and Families Bureau, Ministry of Health, Labour and Welfare. 2016. Reports on infant and young child feeding 2015. Tokyo, Japan: Japanese Ministry of Health, Labour and Welfare. [In Japanese]

Fitzner K. 2007. Reliability and validity: a quick review. Diabetes Educ 33:775-776, 780. 10.1177/0145721707308172

Fox R, McMullen S, and Newburn M. 2015. UK women's experiences of breastfeeding and additional breastfeeding support: a qualitative study of Baby Café services. BMC Pregnancy Childbirth 15:147. 10.1186/s12884-015-0581-5

Grassley JS, Spencer BS, and Bryson D. 2013. The development and psychometric testing of the Supportive Needs of Adolescents Breastfeeding Scale. J Adv Nurs 69:708-716. 10.1111/j.1365-2648.2012.06119.x

Greene SW, and Olson BH. 2008. Development of an instrument designed to measure employees' perceptions of workplace breastfeeding support. Breastfeed Med 3:151-157. 10.1089/bfm.2008.0103

Institute of Medicine. 2000. Promoting Health: Intervention Strategies from Social and Behavioral Research. Washington, DC: The National Academies Press. https://doi.org/10.17226/9939.

Hannula L, Kaunonen M, and Tarkka MT. 2008. A systematic review of professional support interventions for breastfeeding. J Clin Nurs 17:1132-1143. 10.1111/j.13652702.2007.02239.x

House JS. 1981. Work Stress and Social Support. London, United Kingdom: Addison-Wesley Educational Publishers Inc.

Hughes RB. 1984. The development of an instrument to measure perceived emotional, instrumental, and informational support in breastfeeding mothers. Issues Compr Pediatr Nurs 7:357-362.

Inoue M, Binns CW, Otsuka K, Jimba M, and Matsubara M. 2012. Infant feeding practices and breastfeeding duration in Japan: A review. Int Breastfeed J 7:15. 10.1186/1746-4358-715 
560 Ito J, Fujiwara T, and Barr RG. 2013. Is paternal infant care associated with breastfeeding? A

561

562

563

564

565

566

567

568

569

570

571

572

573

574

575

576

577

578

579

580

581

582

583

584

585

586

587

588

589

590

591

592

593

594 population-based study in Japan. J Hum Lact 29:491-499. 10.1177/0890334413488680

Juengst SB, Royston A, Huang I, and Wright B. 2019. Family Leave and Return-to-Work Experiences of Physician Mothers. JAMA Netw Open 2:e1913054.

10.1001/jamanetworkopen.2019.13054

Jyunyuu rinyuu no shien gaido kaitei ni kannsuru kennkyuukai. 2019. Jyunyuu Rinyuu No Shien Gaido-2019 Nenndo Kaiteiban. Tokyo: Ministry of Health, Labour and Welfare. [In Japanese]

Kaneko A, Kaneita Y, Yokoyama E, Miyake T, Harano S, Suzuki K, Ibuka E, Tsutsui T, YukoYamamoto, and Ohida T. 2006. Factors associated with exclusive breast-feeding in Japan: for activities to support child-rearing with breast-feeding. J Epidemiol 16:57-63.

Labbok M, and Krasovec K. 1990. Toward consistency in breastfeeding definitions. Stud Fam Plann 21:226-230.

Labbok M, and Taylor E. 2008. Achieving Exclusive Breastfeeding in the United States: Findings and Recommendations Washington, DC: United States: United States Breastfeeding Committee.

Labbok MH, and Coffin CJ. 1997. A call for consistency in definition of breastfeeding behaviors. Soc Sci Med 44:1931-1932. S0277953697000130 [pii]

Leite AJ, Puccini RF, Atalah AN, Alves Da Cunha AL, and Machado MT. 2005. Effectiveness of home-based peer counselling to promote breastfeeding in the northeast of Brazil: a randomized clinical trial. Acta Paediatr 94:741-746. 10.1111/j.1651-2227.2005.tb01974.x

Matich JR, and Sims LS. 1992. A comparison of social support variables between women who intend to breast or bottle feed. Soc Sci Med 34:919-927. 10.1016/0277-9536(92)90260W

McFadden A, Gavine A, Renfrew MJ, Wade A, Buchanan P, Taylor JL, Veitch E, Rennie AM, Crowther SA, Neiman S, and MacGillivray S. 2017. Support for healthy breastfeeding mothers with healthy term babies. Cochrane Database Syst Rev 2:CD001141. 10.1002/14651858.CD001141.pub5

Ministry of Health, Labour and Welfare. 2011. Survey on the growth of infants and preschool children in Japan, 2010. Tokyo: Equal employment, Children and Families Bureau, Ministry of Health, Labour and Welfare.[In Japanese]

Ministry of Health, Labour and Welfare. 2019a. Vital statistics of population. [In Japanese] Ministry of Health, Labour and Welfare, Director-General for Statistics, Information Policy and Policy Evaluation. 2019b. Outline of Health, Labour and Welfare Statistics, 2019. [In Japanese] 
595 Negron R, Martin A, Almog M, Balbierz A, and Howell EA. 2013. Social support during the

596

597

598

599

600

601

602

603

604

605

606

607

608

609

610

611

612

613

614

615

616

617

618

619 postpartum period: mothers' views on needs, expectations, and mobilization of support. Matern Child Health J 17:616-623. 10.1007/s10995-012-1037-4

Polit DF, Beck CT, and Owen SV. 2007. Is the CVI an acceptable indicator of content validity? Appraisal and recommendations. Res Nurs Health 30:459-467. 10.1002/nur.20199

Robinson K, Fial A, and Hanson L. 2019. Racism, Bias, and Discrimination as Modifiable Barriers to Breastfeeding for African American Women: A Scoping Review of the Literature. J Midwifery Womens Health 64:734-742. 10.1111/jmwh.13058

Sayres S, and Visentin L. 2018. Breastfeeding: uncovering barriers and offering solutions. Curr Opin Pediatr 30:591-596. 10.1097/MOP.0000000000000647

Schmied V, Beake S, Sheehan A, McCourt C, and Dykes F. 2011. Women's perceptions and experiences of breastfeeding support: a metasynthesis. Birth 38:49-60. 10.1111/j.1523536X.2010.00446.X

Sriraman NK, and Kellams A. 2016. Breastfeeding: What are the Barriers? Why Women Struggle to Achieve Their Goals. J Womens Health (Larchmt) 25:714-722. 10.1089/jwh.2014.5059

Toukyouto hukushi hoken kyoku. 2019. Toukyouto kenko suhishin pulan 21 danniji chuukan hyouka hokokusho. Tokyo. [In Japanese]

Unicef. 2019. The State of the World's Children 2019. Children Food and Nutrition: Growing well in a changing world. New York.

Unicef, and World Health Organization. 2018. Implementation guidance: protecting, promoting and supporting breastfeeding in facilities providing maternity and newborn services - the revised Baby-friendly Hospital Initiative. Geneva, Switzerland.

World Health Organization. 2003. Global Strategy for Infant and Young Child Feeding. Geneva, Switzerland. 
Figure 1

Scree plot from factor analysis with the original 31 items

The scree plot from factor analysis with the original 31 items is shown. Because the "elbow" in the curve was at factor number 4 , three factors were retained. 


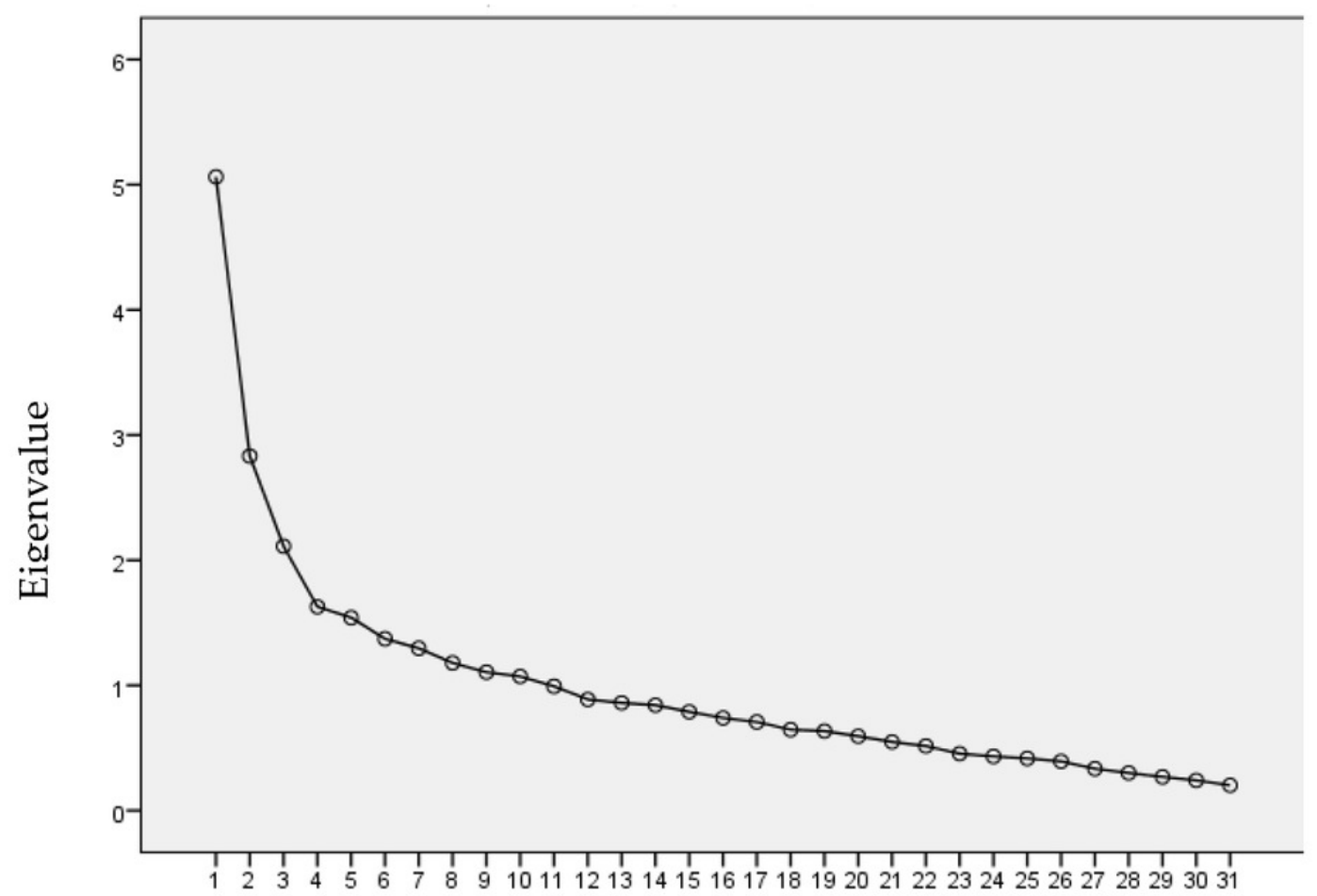

Factor number 


\section{Table $\mathbf{1}$ (on next page)}

Characteristics of participants

The numbers of mothers and the percentages of those who responded are shown. The data are stratified by participaton status: mothers who completed the first survey 3 months postpartum, mothers who returned the follow-up survey 5 months postpartum, and those who were lost to follow-up. The characteristics of those who returned the follow-up questionnaire were compared with the characteristics of those who did not, and the p-values are shown. 
1 Table 1. Characteristics of Participants

2

\begin{tabular}{|c|c|c|c|c|}
\hline & $\begin{array}{l}\text { Completed the } \\
\text { survey } 3 \\
\text { months } \\
\text { postpartum } \\
(\mathrm{n}=243)\end{array}$ & $\begin{array}{l}\text { Completed the } \\
\text { survey } 5 \\
\text { months } \\
\text { postpartum } \\
(\mathrm{n}=177)\end{array}$ & $\begin{array}{l}\text { Dropped out } \\
\text { from the } \\
\text { follow-up } \\
(\mathrm{n}=66)\end{array}$ & $P$ value ${ }^{a}$ \\
\hline $\begin{array}{l}\text { Age in years } \\
\qquad(\text { mean, SD) }\end{array}$ & $31.7(5.0)$ & $32.2(4.4)$ & $30.2(6.2)$ & 0.016 \\
\hline \multicolumn{5}{|c|}{ Country in which participant was raised } \\
\hline Japan & $233(95.9 \%)$ & $172(97.2 \%)$ & $61(92.4 \%)$ & 0.140 \\
\hline Others & $10(4.1 \%)$ & $5(2.8 \%)$ & $5(7.6 \%)$ & \\
\hline \multicolumn{5}{|l|}{ Highest level of schooling } \\
\hline Junior high & $11(4.5 \%)$ & $4(2.3 \%)$ & $7(10.8 \%)$ & 0.002 \\
\hline High school & $53(21.8 \%)$ & $34(19.2 \%)$ & $19(29.2 \%)$ & \\
\hline $\begin{array}{l}\text { College }^{\mathrm{b}} \text { or } \\
\text { equivalent }\end{array}$ & $88(36.2 \%)$ & $64(36.2 \%)$ & $24(36.9 \%)$ & \\
\hline University $^{\mathrm{c}}$ or higher & $90(37.0 \%)$ & $75(42.4 \%)$ & $15(23.1 \%)$ & \\
\hline \multicolumn{5}{|l|}{ Financial status } \\
\hline No financial worries & $38(15.6 \%)$ & $25(14.1 \%)$ & $13(19.7 \%)$ & 0.138 \\
\hline Not very worried & $84(34.6 \%)$ & $68(38.4 \%)$ & $16(24.2 \%)$ & \\
\hline Somewhat worried & $89(36.6 \%)$ & $64(36.2 \%)$ & $25(37.9 \%)$ & \\
\hline Worried & $32(13.2 \%)$ & $20(11.3 \%)$ & $12(18.2 \%)$ & \\
\hline \multicolumn{5}{|l|}{ Marital Status } \\
\hline $\begin{array}{l}\text { Married or having a } \\
\text { steady partner }\end{array}$ & $234(96.3 \%)$ & $173(97.7 \%)$ & $61(92.4 \%)$ & 0.037 \\
\hline \multicolumn{5}{|l|}{ Delivery mode } \\
\hline Vaginal delivery & $197(81.1 \%)$ & $143(81.7 \%)$ & $54(83.1 \%)$ & 0.807 \\
\hline Caesarian section & $43(17.7 \%)$ & $32(18.3 \%)$ & $11(16.9 \%)$ & \\
\hline \multicolumn{5}{|l|}{ Intention to breastfeed $^{\mathrm{d}}$} \\
\hline $\begin{array}{l}\text { Exclusive } \\
\text { breastfeeding }\end{array}$ & $157(65.6 \%)$ & $112(63.3 \%)$ & $45(68.2 \%)$ & 0.477 \\
\hline Partial breastfeeding & $86(35.4 \%)$ & $65(36.7 \%)$ & $21(31.8 \%)$ & \\
\hline Primipara & $144(59.3 \%)$ & $105(59.3 \%)$ & $39(59.1 \%)$ & 0.424 \\
\hline Previous experience of & $84(34.9 \%)$ & $60(34.3 \%)$ & $24(36.4 \%)$ & 0.763 \\
\hline
\end{tabular}




\begin{tabular}{|c|c|c|c|c|}
\hline $\begin{array}{l}\text { breastfeeding a baby for } \\
\text { more than } 5 \text { months }\end{array}$ & & & & \\
\hline \multicolumn{5}{|l|}{ Working status } \\
\hline $\begin{array}{l}\text { Working at } 3 \text { months } \\
\text { postpartum }\end{array}$ & $14(5.9 \%)$ & $6(3.4 \%)$ & $8(12.7 \%)$ & 0.094 \\
\hline $\begin{array}{l}\text { Planning to return to } \\
\text { work before } 6 \\
\text { months postpartum }\end{array}$ & $12(4.9 \%)$ & $9(5.1 \%)$ & $3(4.8 \%)$ & \\
\hline $\begin{array}{l}\text { Planning to return to } \\
\text { work after } 6 \text { months } \\
\text { postpartum }\end{array}$ & $108(45.2 \%)$ & $83(47.2 \%)$ & $25(39.7 \%)$ & \\
\hline No plan to work & $105(43.2 \%)$ & $78(44.3 \%)$ & $27(42.9 \%)$ & \\
\hline
\end{tabular}

3 a Comparison between those who returned and did not return the follow-up questionnaire.

4 b Typically a two-year course after high school.

$5 \quad$ c Typically a four-year course after high school.

6 d Those who intended formula feeding were excluded from the analysis.

7 


\section{Table 2 (on next page)}

Infant feeding status 3 months and 5 months postpartum

The numbers of mothers and the percentages of those who responded are shown, by infant feeding status 3 months postpartum and 5 months postpartum. Infant feeding status is shown in six categories. 
2 Table 2. Infant feeding status 3 months and 5 months postpartum

3

\begin{tabular}{|l|c|c|}
\hline \multicolumn{1}{|c|}{ Infant feeding status at the time of the survey } & $\begin{array}{c}3 \text { months } \\
(\mathrm{n}=242)\end{array}$ & $\begin{array}{c}5 \text { months } \\
(\mathrm{n}=177)\end{array}$ \\
\hline $\begin{array}{l}\text { Breast milk only } \\
\text { (exclusive and almost exclusive) }\end{array}$ & $\begin{array}{c}137 \\
(56.6 \%)\end{array}$ & $\begin{array}{c}109 \\
(61.6 \%)\end{array}$ \\
\hline $\begin{array}{l}\text { High partial breastfeeding } \\
\text { (breastfeeding for more than 80\% of all feedings) }\end{array}$ & $\begin{array}{c}49 \\
(20.2 \%)\end{array}$ & $\begin{array}{c}23 \\
(13.0 \%)\end{array}$ \\
\hline $\begin{array}{l}\text { Middle partial breastfeeding } \\
\text { (breastfeeding for 20\%-80\% of all feedings) }\end{array}$ & 24 & 23 \\
\hline $\begin{array}{l}\text { Low partial breastfeeding } \\
\text { (breastfeeding for less than 20\% of all feedings) }\end{array}$ & $(9.9 \%)$ & $(13.0 \%)$ \\
\hline $\begin{array}{l}\text { Token feeding } \\
\text { (occasional breastfeeding, not for nutritive purposes) }\end{array}$ & $(1.7 \%)$ & 6 \\
\hline $\begin{array}{l}\text { Formula feeding } \\
\text { (only formula feeding only) }\end{array}$ & 22 & $(3.4 \%)$ \\
\hline
\end{tabular}

4 
Table 3(on next page)

Distribution of scores on each item

The mean score and the standard deviation of scores is shown for each item. 
1 Table 3. Distribution of scores on each item

2

\begin{tabular}{|c|c|c|c|}
\hline $\begin{array}{l}\text { Item } \\
\text { Number }\end{array}$ & Item $^{\mathrm{a}}$ & Mean $^{b}$ & $\begin{array}{l}\text { Standard } \\
\text { Deviation }\end{array}$ \\
\hline 1 & $\begin{array}{l}\text { There is someone with whom I can easily and openly } \\
\text { discuss breastfeeding. }\end{array}$ & 4.30 & 1.12 \\
\hline 2 & $\begin{array}{l}\text { There is someone who helps with other child care and } \\
\text { with housework such that it's easy for me to make } \\
\text { time to breastfeed my baby. }\end{array}$ & 3.31 & 1.46 \\
\hline 3 & $\begin{array}{l}\text { There is someone close to you who gives you } \\
\text { emotional support in breastfeeding. }\end{array}$ & 3.89 & 1.24 \\
\hline 4 & $\begin{array}{l}\text { There is someone who tells me about positive } \\
\text { experiences of breastfeeding }\end{array}$ & 3.47 & 1.45 \\
\hline 5 & $\begin{array}{l}\text { There is someone who helps you with other child care } \\
\text { and with housework such that it's easy for you to take } \\
\text { care of your baby. }\end{array}$ & 3.68 & 1.39 \\
\hline $6^{c}$ & $\begin{array}{l}\text { I have received free samples or discount coupons for } \\
\text { formula milk. }\end{array}$ & 2.48 & 1.65 \\
\hline 7 & $\begin{array}{l}\text { If necessary, there is someone other than family or } \\
\text { friends (e.g. health care provider, breastfeeding } \\
\text { support group member) whom I can consult on } \\
\text { breastfeeding. }\end{array}$ & 3.69 & 1.48 \\
\hline 8 & $\begin{array}{l}\text { Most health care providers (doctors, public health } \\
\text { nurses, midwives, etc.) support you in breastfeeding. }\end{array}$ & 3.94 & 1.08 \\
\hline 9 & $\begin{array}{l}\text { Health care providers including doctors, public health } \\
\text { nurses, or midwives tell me about the benefits of } \\
\text { breastfeeding. }\end{array}$ & 3.99 & 1.12 \\
\hline 10 & I can breastfeed comfortably when I'm out and about. & 3.47 & 1.33 \\
\hline $11^{c}$ & $\begin{array}{l}\text { I see formula milk with product information saying } \\
\text { that breastmilk and artificial milk do not differ much } \\
\text { in their health benefits for babies. }\end{array}$ & 2.22 & 1.25 \\
\hline $12^{c}$ & $\begin{array}{l}\text { I have received advice regarding infant feeding from } \\
\text { people employed by the dairy industry ("advisors", } \\
\text { nutritionists, etc.). }\end{array}$ & 3.44 & 1.47 \\
\hline 13 & $\begin{array}{l}\text { Information from books, magazines, and the Internet } \\
\text { is useful for breastfeeding. }\end{array}$ & 3.86 & 1.09 \\
\hline $14^{\mathrm{c}}$ & $\begin{array}{l}\text { Sometimes I provide something other than } \\
\text { breastmilk to my baby because housework or } \\
\text { parenting of an elder child gets in the way. }\end{array}$ & 3.80 & 1.53 \\
\hline $15^{c}$ & $\begin{array}{l}\text { Information from television, newspapers, etc. } \\
\text { sometimes makes me anxious about breastfeeding. }\end{array}$ & 4.25 & 1.14 \\
\hline $16^{\mathrm{c}}$ & $\begin{array}{l}\text { There is someone close to me who encourages me to } \\
\text { wean my baby from the breast soon. }\end{array}$ & 4.55 & 0.94 \\
\hline 17 & $\begin{array}{l}\text { There is someone I can talk with whenever I have } \\
\text { issues with breastfeeding. }\end{array}$ & 3.95 & 1.25 \\
\hline $18^{\mathrm{c}}$ & I have heard that I must not take any medicine while & 3.42 & 1.47 \\
\hline
\end{tabular}




\begin{tabular}{|c|c|c|c|}
\hline & breastfeeding. & & \\
\hline $19^{c}$ & $\begin{array}{l}\text { There are discrepancies among what health care } \\
\text { providers (doctors, public health nurses, midwives, } \\
\text { etc.) say about breastfeeding. }\end{array}$ & 2.76 & 1.28 \\
\hline $20^{c}$ & $\begin{array}{l}\text { In medical facilities I see posters or logos about } \\
\text { formula milk. }\end{array}$ & 2.78 & 1.51 \\
\hline $21^{c}$ & $\begin{array}{l}\text { Information on breastfeeding from mass media or the } \\
\text { Internet confuses me. }\end{array}$ & 3.32 & 1.39 \\
\hline $22^{c}$ & $\begin{array}{l}\text { I have heard that there are certain things I should not } \\
\text { eat while breastfeeding. }\end{array}$ & 2.07 & 1.21 \\
\hline $23^{c}$ & $\begin{array}{l}\text { There is someone close to me who encourages me to } \\
\text { provide something other than breastmilk to my baby. }\end{array}$ & 3.75 & 1.44 \\
\hline $24^{c}$ & $\begin{array}{l}\text { I have trouble finding places to breastfeed when I'm } \\
\text { out and about. }\end{array}$ & 2.30 & 1.24 \\
\hline $25^{c}$ & $\begin{array}{l}\text { According to product information regarding formula } \\
\text { milk, giving formula milk has health benefits for } \\
\text { babies. }\end{array}$ & 2.57 & 1.12 \\
\hline 26 & $\begin{array}{l}\text { There are people around you who help you get } \\
\text { enough rest. }\end{array}$ & 3.67 & 1.22 \\
\hline 27 & I can breastfeed my baby comfortably at home. & 4.71 & 0.62 \\
\hline $28^{c}$ & $\begin{array}{l}\text { When I leave my baby with other people, I think it will } \\
\text { be problematic for them if my baby does not accept a } \\
\text { bottle of formula milk. }\end{array}$ & 1.78 & 1.15 \\
\hline $29^{c}$ & I feel pressured to breastfeed my baby. & 3.70 & 1.41 \\
\hline 30 & $\begin{array}{l}\text { There are services from the city or other local } \\
\text { government that help me take care of my baby. }\end{array}$ & 3.60 & 1.10 \\
\hline 31 & $\begin{array}{l}\text { If necessary, I can consult with health care providers } \\
\text { (doctors, public health nurses, midwives, etc.) on how } \\
\text { to breastfeed. }\end{array}$ & 3.79 & 1.16 \\
\hline
\end{tabular}

3 aEach item was developed and presented in Japanese. The text in the table was

4 translated into English by the authors. The English translation provided here is to be 5 used not for collecting data, but rather for informational purposes only. It has not been 6 tested in English for use among English-speaking mothers. For example, in the English 7 translation provided here, some items contain "l" while others contain "you". Neither the 8 developers nor the users found the mix of the corresponding Japanese expressions to 9 be unacceptable, but the wording might be standardized to use only "l" or only "you" if 10 the instrument were to be tested in English and used in English.

11 bEach item's score can range from 1 to 5 .

$12{ }^{\mathrm{c}}$ These items were negatively worded. Their scores were reversed, such that higher 13 scores indicate more support. 


\section{Table 4 (on next page)}

Factor loadings of 11 items after varimax rotation

The factor loadings of the 11 items after varimax rotation are shown. 
2 Table 4. Factor loadings of 11 items after varimax rotation

3

\begin{tabular}{|c|c|c|c|c|}
\hline $\begin{array}{l}\text { Item } \\
\text { number }\end{array}$ & Item content ${ }^{a}$ & Factor $1^{b}$ & Factor $2^{c}$ & Factor $3^{d}$ \\
\hline 7 & $\begin{array}{l}\text { If necessary, there is someone other than } \\
\text { family or friends (e.g. health care } \\
\text { provider, breastfeeding support group } \\
\text { member) whom I can consult on } \\
\text { breastfeeding. }\end{array}$ & .576 & .072 & .244 \\
\hline 8 & $\begin{array}{l}\text { Most health care providers (doctors, } \\
\text { public health nurses, midwives, etc.) } \\
\text { support you in breastfeeding. }\end{array}$ & .842 & -.011 & .097 \\
\hline 9 & $\begin{array}{l}\text { Health care providers including doctors, } \\
\text { public health nurses, or midwives tell } \\
\text { me about the benefits of breastfeeding. }\end{array}$ & .730 & .079 & .133 \\
\hline 31 & $\begin{array}{l}\text { If necessary, I can consult with health } \\
\text { care providers (doctors, public health } \\
\text { nurses, midwives, etc.) on how to } \\
\text { breastfeed. }\end{array}$ & .586 & .023 & .199 \\
\hline 2 & $\begin{array}{l}\text { There is someone who helps with other } \\
\text { child care and with housework such that } \\
\text { it's easy for me to make time to } \\
\text { breastfeed my baby. }\end{array}$ & -.003 & .831 & .192 \\
\hline 5 & $\begin{array}{l}\text { There is someone who helps you with } \\
\text { other child care and with housework } \\
\text { such that it's easy for you to take care of } \\
\text { your baby. }\end{array}$ & .029 & .855 & .139 \\
\hline 26 & $\begin{array}{l}\text { There are people around you who help } \\
\text { you get enough rest. }\end{array}$ & .093 & .501 & .279 \\
\hline 1 & $\begin{array}{l}\text { There is someone with whom I can } \\
\text { easily and openly discuss breastfeeding. }\end{array}$ & .120 & .192 & .776 \\
\hline 3 & $\begin{array}{l}\text { There is someone close to you who gives } \\
\text { you emotional support in breastfeeding. }\end{array}$ & .193 & .378 & .571 \\
\hline 4 & $\begin{array}{l}\text { There is someone who tells me about } \\
\text { positive experiences of breastfeeding. }\end{array}$ & .353 & .261 & .507 \\
\hline 17 & There is someone I can talk with & .354 & .162 & .698 \\
\hline
\end{tabular}


whenever I have issues with

breastfeeding.

4

5 a English translation of the questions asked.

6 b Considered to comprise a subscale measuring support from breastfeeding peers and

7 from people in specifically named professionals.

8 c Considered to comprise a subscale measuring practical help.

9 d Considered to comprise a subscale measuring support from people the mother can rely

10 on to help meet emotional needs and address breastfeeding concerns. 


\section{Table 5 (on next page)}

Scores on the 11-item scale, measured 3 months postpartum, by infant-feeding status 3 months and 5 months postpartum

Means of total scores measured 3 months postpartum are shown, by infant feeding status. The scores 3 months postpartum are shown in the upper lines and the scores 5 months postpartum are shown in the lower lines. 
1

2 Table 5. Scores on the 11-item scale, measured 3 months postpartum, by infant-feeding

3 status 3 months and 5 months postpartum

4

\begin{tabular}{|l|c|c|}
\hline \multicolumn{1}{|c|}{ Infant-feeding status } & $\mathrm{n}\left(\%^{\mathrm{a}}\right)$ & $\begin{array}{c}\text { Total score } \\
\text { Mean (SD) }\end{array}$ \\
\hline 3 months postpartum & & \\
\hline Full breastfeeding & $132(62.6)$ & $42.6(8.7)$ \\
\hline High-partial breastfeeding & $46(21.8)$ & $41.9(6.9)$ \\
\hline Medium-partial breastfeeding & $21(10.0)$ & $37.8(8.0)$ \\
\hline $\begin{array}{l}\text { Low-partial breastfeeding, token breastfeeding, or } \\
\text { formula feeding }\end{array}$ & $12(5.7)$ & $33.3(10.4)$ \\
\hline 5 months postpartum & & \\
\hline Full breastfeeding & $104(61.6)$ & $41.9(8.9)$ \\
\hline High-partial breastfeeding & $22(13.0)$ & $43.6(7.1)$ \\
\hline Medium-partial breastfeeding & $22(13.0)$ & $40.3(6.3)$ \\
\hline $\begin{array}{l}\text { Low-partial breastfeeding, token breastfeeding, or } \\
\text { formula feeding }\end{array}$ & $11(12.4)$ & $35.4(8.4)$ \\
\hline
\end{tabular}

5

6 a Among those who completed the scale 3 months postpartum and also reported

7 feeding status at the time of the survey.

8

9 